\title{
Outcomes of Posterior Wall Thickness, Interventricular Septal Thickness and LA diameter after Surgical Closure of Ventricular Septal Defect in Different Age Group
}

\author{
MD. AMINULLAH ${ }^{1}$, SWADESH RANJAN SARKER ${ }^{2}$, RAKIBUL HASAN ${ }^{3}$, MAHBUBUR RAHMAN $^{4}$, \\ REZWANULHOQUE ${ }^{1}$
}

\begin{abstract}
${ }^{1}$ Department of Cardiac Surgery, Bangabandhu Sheikh Mujib Medical University, Dhaka. ${ }^{2}$ Department of Vascular Surgery, National Institute of Cardiovascular Diseases, Dhaka. ${ }^{3}$ Department of Vascular Surgery, Bangabandhu Sheikh Mujib Medical University, Dhaka. ${ }^{4}$ Department of Cardiac Surgery, National Institute of Cardiovascular Diseases, Dhaka.
\end{abstract}

Addess for Correspondance: Md. Aminullah, Department of Cardiac Surgery, Bangabandhu Sheikh Mujib Medical University, Dhaka.

\begin{abstract}
Background: Good outcome after surgical closure of ventricular septal defect is essential. Objective: The purpose of the present study was to see the improvement of posterior wall thickness, interventricular septal thickness and LA diameter after surgical closure of ventricular septal defect in different age group. Methodology: This prospective cohort studies was conducted in the Department of Cardiac Surgery at National Institute of Cardiovascular Disease (NICVD), Dhaka. Patient with surgical closure of VSD were enrolled into this study purposively and were divided into 3 groups according to the age. In group $A(n=10)$, patients were within the age group of 2.0 to 6.0 years; age of group $B(n=8)$ patients were 6.1-18.0 years and the group $C(n=6)$ ages range was 18.1-42.0 years. Echocardiographic variables such as posterior wall thickness, interventricular septal thickness and LA diameter were taken preoperatively and at $1^{\text {st }}$ and $3^{\text {rd }}$ month of postoperative values. Result: Totally 24 patients were recruited for this study. The mean age was 12.60 \pm 12.09 . After 1 month posterior wall thickness was increased by $12.07 \%, 7.02 \%$ and $5.26 \%$ in group A, group B and group C respectively. After 3 months left ventricular posterior wall thickness was decreased by $36.21 \%, 29.78 \%$ and $17.58 \%$ in group A, group B and group C respectively. After 1 month interventricular septal thickness was increased by 3.51\%, $8.86 \%$ and $9.22 \%$ in group $A$, group $B$ and group $C$ respectively. After 3 months interventricular septal thickness was decreased by $31.58 \%, 25.00 \%$ and $16.67 \%$ in group $A$, group B and group C respectively. After 1 month $L A$ diameter was increased by $4.81 \%, 4.28 \%$ and $4.75 \%$ in group $A$, group $B$ and group $C$ respectively. After 3 months $L A$ diameter was decreased by 15.93\%, 12.84\% and 5.96\% in group A, group B and group C respectively. Conclusion: Cardiac remodeling occurred after surgical closure of ventricular septal defect and remodeling were more significant in younger age group.
\end{abstract}

Keywords: Cardiac remodeling; ventricular septal defect; surgical closure; echocardiographic evaluation

Introduction:

Ventricular septal defect (VSD) is a common congenital heart defect in both children and adults ${ }^{1}$. Management of this lesion has changed dramatically in the last 50 years ${ }^{2}$. Catheter-based therapy for VSD closure, now in the clinical trial phase, is another step in the evolution of treatment for this disorder. Despite these advances, many patients with small VSDs require only sub acute bacterial endocarditis prophylaxis ${ }^{3}$.

It has been reported that the most common form of congenital heart disease in childhood is the VSD, occurring in $50 \%$ of all children with congenital heart disease and in $20 \%$ as an isolated lesion ${ }^{4}$. The incidence of VSDs has been increased dramatically with advances in imaging and screening of infants and these ranges from 1.56 to 53.2 per 1000 live births ${ }^{5}$. The ease of detection of small muscular
VSDs is reflected in the higher incidence rates. A large review of the literature estimated the median incidence of VSDs at 2829 per 1 million live births ${ }^{6}$. In the adult population, VSDs are the most common congenital heart defect excluding the bicuspid aortic valve ${ }^{7}$. Task Force 1 estimated the prevalence of simple VSDs in the adult population as 0.3 per $1000^{8}$. The number of adults in the United States with simple congenital heart lesions was estimated to be $368800^{8}$. Another study by Hoffman et $\mathrm{al}^{9}$ also estimated the number of surviving adults by decade with either small or large VSDs.

Echocardiographic evaluation of VSDs is a noninvasive tool that accurately delineates the morphology and associated defects ${ }^{10}$. Hemodynamic evaluation of the defect, the presence of elevated pulmonary artery pressure, obstruction of the right ventricular outflow tract 
double chamber physiology, insufficiency of the aortic valve, and distortion of the valve apparatus are all evaluated by echocardiography ${ }^{11}$. When limitations in image quality of transthoracic echocardiography prevent evaluation of these aspects of the cardiovascular physiology, transesophageal imaging can be performed. Threedimensional echocardiography has proved accurate for quantifying shunt and can provide accurate visualization of defects that otherwise are difficult to evaluate by 2dimensional imaging alone.

It is very logical to assume that the degree of compensatory changes in the heart depends on the size and flow across the VSD, the relative compliance, pressure and resistance to flow in the ventricles and the greater the duration of this left to right shunt, greater the adaptive changes. Therefore, early intervention is very likely to holt the disease process and thereby the pathological changes and the magnitude of cardiac remodeling is expected to be more compete as a logical consequence. The purpose of the present study was to see the improvement of posterior wall thickness, interventricular septal thickness and LA diameter after surgical closure of ventricular septal defect in different age group.

\section{Methodology:}

This study was designed as prospective cohort study and was carried out from January 2014 to May 2014 for a period of five (5) months. This study was conducted in the Department of Cardiac Surgery at National Institute of Cardiovascular Disease (NICVD) Dhaka. All patients presented with isolated VSD who were surgically treated with the age group of 2 to 42 years of both sexes were included as study population. This study population was divided into 3 groups on the basis of preschool going child, school going child and adult which were designated as group $\mathrm{A}$, group $\mathrm{B}$ and group $\mathrm{C}$ respectively. VSD patients with other associated cardiac diseases and patients with pulmonary artery systolic pressure (PASP) more than $60 \mathrm{~mm}$ of $\mathrm{Hg}$ was excluded from this study. The sampling technique was purposive sampling method. After getting written informed consent from adult and the guardians of the children, all data regarding demographic variables, echocardiographic variables were collected. Mmode and two-dimensional echocardiography recordings were performed using a phased-array echocardiographic Doppler system (Sonos 5500, Hewlett-Packard [Agilent], Andover, Massachusetts) equipped with a 3-7 $\mathrm{MHz}$ transducer. Echocardiography was done in left lateral recumbent position using standard parasternal short- and long-axis and apical views. Posterior wall thickness, interventricular septal thickness and LA diameter were recorded by echocardiography. All patients were followed up 1 month and 3 months after postoperative days by echocardiography and compared with preoperative echocardiographic findings. Data were collected using a preformed data collection sheet. Baseline information was collected from the patient after exploration of different complaints and sign and symptoms of the cardiovascular diseases. Prior to the commencement of this study, the research protocol was approved by the ethical committee (Institutional Review Board) of BSMMU. Statistical analysis was performed by using window based computer software with Statistical Packages for Social Sciences (SPSS-12) (SPSS Inc, Chicago, IL, USA). Probability values $<0.05$ were considered as level of significance.

\section{Results:}

This prospective cohort study was carried out in the Department of Cardiac Surgery at National Institute of Cardiovascular Disease (NICVD), Dhaka. Total 24 VSD surgically treated patients were included who were divided into three groups according to age. Patients within the age group 2.0 to 6.0 years belonged to group A, 6.1 to 18.0 years belonged to group B and 18.1 to 42.0 years belonged to group C. This study was conducted on patients with age ranging from 2 to 42 years with a mean (SD) of all age group $12.60 \pm 12.09$ years (Table 1 ).

Table-I

Distribution of Patients by Age $(n=24)$

\begin{tabular}{lcc}
\hline Age (years) & Frequency & Percent \\
\hline Group A & 10 & 41.7 \\
Group B & 8 & 33.3 \\
Group C & 6 & 25.0 \\
Total & 24 & 100.0 \\
Mean \pm SD & $12.60 \pm 12.09(2-42$ years $)$ & \\
\hline
\end{tabular}

In group A the mean $( \pm \mathrm{SD})$ left ventricular posterior wall thickness was higher after 1 month of operation $(6.50 \pm$ $1.35 \mathrm{~mm})$ than that of preoperative $(5.80 \pm 1.03 \mathrm{~mm})$. It was significantly smaller after 3 months of operation $(3.70 \pm$ $0.67 \mathrm{~mm})$ than that of preoperative $(5.80 \pm 1.03 \mathrm{~mm})(\mathrm{p}<0.05)$. In group $B$ the mean $( \pm \mathrm{SD})$ left ventricular posterior wall thickness was higher after 1 month of operation (7.62 \pm $0.91 \mathrm{~mm})$ than that of preoperative $(7.12 \pm 1.24 \mathrm{~mm})$. It was significantly smaller after 3 months of operation $(5.00 \pm$ $1.06 \mathrm{~mm})$ than that of preoperative $(7.12 \pm 1.24 \mathrm{~mm})(\mathrm{p}<0.05)$. In group $\mathrm{C}$ the mean $( \pm \mathrm{SD})$ left ventricular posterior wall thickness was higher after 1 month of operation (10.00 \pm 
$0.89 \mathrm{~mm})$ than that of preoperative $(9.50 \pm 0.83 \mathrm{~mm})$ and it was significantly smaller after 3 months of operation ( 7.83 $\pm 1.16 \mathrm{~mm})$ than that of preoperative $(9.50 \pm 0.83 \mathrm{~mm})$ patients. After 1 month posterior wall thickness was increased by $12.07 \%, 7.02 \%$ and $5.26 \%$ in group A, group $\mathrm{B}$ and group $\mathrm{C}$ respectively. After 3 months left ventricular posterior wall thickness was decreased by $36.21 \%, 29.78 \%$ and $17.58 \%$ in group A, group B and group $\mathrm{C}$ respectively (Table 2).

Interventricular septal thickness was measured preoperatively and postoperatively after 1 and 3 month. In group A mean $( \pm \mathrm{SD})$ interventricular septal thickness of preoperative and postoperative after 1 and 3 month were $5.70 \pm 0.48 \mathrm{~mm}, 5.90 \pm 0.73 \mathrm{~mm}$ and $3.90 \pm 0.73 \mathrm{~mm}$ respectively. In group B the mean $( \pm \mathrm{SD})$ interventricular septal thickness of preoperatively and postoperative after 1 and 3 month were $7.00 \pm 0.75 \mathrm{~mm}, 7.62 \pm 1.18 \mathrm{~mm}$ and 5.25 $\pm 0.46 \mathrm{~mm}$ respectively. In group $\mathrm{C}$ the mean $( \pm \mathrm{SD})$ interventricular septal thickness of preoperatively and postoperative after 1 and 3 month were $9.00 \pm 1.09 \mathrm{~mm}$, $9.83 \pm 1.16 \mathrm{~mm}$ and $7.50 \pm 1.51 \mathrm{~mm}$ respectively. After 1 month interventricular septal thickness was increased by $3.51 \%, 8.86 \%$ and $9.22 \%$ in group A, group B and group C respectively but after 3 months it was decreased by $31.58 \%$, $25.00 \%$ and $16.67 \%$ in group A, group B and group C respectively (Table 3 ).

LA diameter was measured preoperatively and postoperatively after 1 and 3 month. In group A mean $( \pm$ SD) LA diameter of preoperative and postoperative after 1 and 3 month were $27.00( \pm 4.32) \mathrm{mm}, 28.30( \pm 4.42) \mathrm{mm}$ and $22.70( \pm 3.09) \mathrm{mm}$ respectively. In group B the mean $( \pm \mathrm{SD})$ LA diameter of preoperatively and postoperative after 1 and 3 month were $23.37( \pm 2.38) \mathrm{mm}, 24.37( \pm 2.44) \mathrm{mm}$ and $20.37 \pm 3.02 \mathrm{~mm}$ respectively. In group $C$ the mean $( \pm \mathrm{SD})$ LA diameter of preoperatively and postoperative after 1 and 3 month were $28.00( \pm 2.00) \mathrm{mm}, 29.33( \pm 2.33) \mathrm{mm}$ and $26.33 \pm 1.63 \mathrm{~mm}$ respectively. After 1 month LA diameter was increased by $4.81 \%, 4.28 \%$ and $4.75 \%$ in group A, group $\mathrm{B}$ and group $\mathrm{C}$ respectively but after 3 months decreased by $15.93 \%, 12.84 \%$ and $5.96 \%$ in group A, group $\mathrm{B}$ and group $\mathrm{C}$ respectively (Table 4).

Table-II

Preoperative and postoperative comparison of left ventricular posterior wall thickness $(n=24)$

\begin{tabular}{|c|c|c|c|c|c|c|}
\hline \multirow[t]{2}{*}{ Group } & \multicolumn{3}{|c|}{$\begin{array}{l}\text { Posterior wall thickness (mm) } \\
(\text { Mean } \pm \text { SD) }\end{array}$} & \multirow[t]{2}{*}{$\begin{array}{l}\text { p-value } \\
\text { (A vs C) }\end{array}$} & \multicolumn{2}{|c|}{$\begin{array}{l}\text { Changes in } \\
\text { percentage }\end{array}$} \\
\hline & $\begin{array}{c}\text { Preoperative } \\
{[\mathrm{A}]}\end{array}$ & $\begin{array}{l}\text { Postoperative } \\
\text { (after } 1 \text { mon) [B] }\end{array}$ & $\begin{array}{l}\text { Postoperative } \\
\text { (after } 3 \text { mon) }[\mathrm{C}]\end{array}$ & & $\begin{array}{c}\text { After } \\
1 \text { month }\end{array}$ & $\begin{array}{c}\text { After } \\
3 \text { months } \\
\end{array}$ \\
\hline Group A & $5.80 \pm 1.03$ & $6.50 \pm 1.35$ & $3.70 \pm 0.67$ & 0.001 & +12.07 & -36.21 \\
\hline Group B & $7.12 \pm 1.24$ & $7.62 \pm 0.91$ & $5.00 \pm 1.06$ & 0.001 & +7.02 & -29.78 \\
\hline Group C & $9.50 \pm 0.83$ & $10.00 \pm 0.89$ & $7.83 \pm 1.16$ & 0.001 & +5.26 & -17.58 \\
\hline
\end{tabular}

*One way ANOVA was done to measure the level of significance

Table-III

Preoperative and postoperative comparison of interventricular septal thickness $(n=24)$

\begin{tabular}{|c|c|c|c|c|c|c|}
\hline \multirow[t]{2}{*}{$\overline{\text { Group }}$} & \multicolumn{3}{|c|}{$\begin{array}{l}\text { Interventricular septal thickness in mm } \\
(\text { Mean } \pm \text { SD) }\end{array}$} & \multirow[t]{2}{*}{$\begin{array}{l}\text { p-value } \\
\text { (A vs C) }\end{array}$} & \multicolumn{2}{|c|}{$\begin{array}{l}\text { Changes in } \\
\text { percentage }\end{array}$} \\
\hline & $\begin{array}{l}\text { Preoperative } \\
\text { [A] }\end{array}$ & $\begin{array}{l}\text { Postoperative } \\
\text { (after } 1 \text { mon) }[\mathrm{B}]\end{array}$ & $\begin{array}{l}\text { Postoperative } \\
\text { (after } 3 \text { mon) }[\mathrm{C}]\end{array}$ & & $\begin{array}{c}\text { After } \\
1 \text { month }\end{array}$ & $\begin{array}{c}\text { After } \\
3 \text { months }\end{array}$ \\
\hline Group A & $5.70 \pm 0.48$ & $5.90 \pm 0.73$ & $3.90 \pm 0.73$ & 0.0001 & +3.51 & -31.58 \\
\hline Group B & $7.00 \pm 0.75$ & $7.62 \pm 1.18$ & $5.25 \pm 0.46$ & 0.0001 & +8.86 & -25.00 \\
\hline Group C & $9.00 \pm 1.09$ & $9.83 \pm 1.16$ & $7.50 \pm 1.51$ & 0.0001 & +9.22 & -16.67 \\
\hline
\end{tabular}

*One way ANOVA was done to measure the level of significance 
Table-IV

Preoperative and postoperative comparison of LA diameter $(n=24)$

\begin{tabular}{lcccccc}
\hline Group & \multicolumn{3}{c}{$\begin{array}{c}\text { LA diameter in } \mathrm{mm} \\
(\text { Mean } \pm \text { SD) }\end{array}$} & $\begin{array}{c}\text { p-value } \\
\text { (A vs C) }\end{array}$ & \multicolumn{2}{c}{$\begin{array}{c}\text { Changes in } \\
\text { percentage }\end{array}$} \\
& $\begin{array}{c}\text { Preoperative } \\
\text { Postoperative } \\
\text { (after 1 mon) }[\mathrm{B}]\end{array}$ & $\begin{array}{c}\text { Postoperative } \\
\text { (after 3 mon) }[\mathrm{C}]\end{array}$ & & $\begin{array}{c}\text { After } \\
1 \text { month }\end{array}$ & $\begin{array}{c}\text { After } \\
\text { months }\end{array}$ \\
\hline Group A & $27.00 \pm 4.32$ & $28.30 \pm 4.42$ & $22.70 \pm 3.09$ & 0.001 & +4.81 & -15.93 \\
Group B & $23.37 \pm 2.38$ & $24.37 \pm 2.44$ & $20.37 \pm 3.02$ & 0.001 & +4.28 & -12.84 \\
Group C & $28.00 \pm 2.00$ & $29.33 \pm 2.33$ & $26.33 \pm 1.63$ & 0.001 & +4.75 & -5.96 \\
\hline
\end{tabular}

*One way ANOVA was done to measure the level of significance

\section{Discussion:}

Ventricular septal defect (VSD) is a common congenital anomaly which requires early closure by various methods ${ }^{12}$. In this study 24 patients of different age group who had undergone ventricular septal defect closure by surgery were enrolled. Echocardiographic evaluation was done before operation and 1 month and 3 months after surgical closure of VSD in different age group.

This study was conducted in the Department of cardiac surgery, NICVD. The enrolled patients were divided into three groups as 2.0- 6.0 years $(\mathrm{n}=10)$ in group $\mathrm{A}$, other were 6.1-18.0 years $(n=8)$ in group $B$ and 18.1-42.0 years $(n=6)$ in group $C$, after data collection. The age of the enrolled patients ranged from 2 to 42 years, with a mean age of all group $12.60 \pm 12.09$ years, majority of patients in the range of 2.0-6.0 years (41.7\%), other were 6.1-18.0 years (33.3\%) and $18.1-42.0$ years $(25 \%)$.

Left ventricular posterior wall thickness increased from preoperative values to $1^{\text {st }}$ month of postoperative values in three groups. After 1 month it was increased by $12.07 \%$, $7.02 \%$ and $5.26 \%$ in group A, group B and group C respectively. It was significantly declined from preoperative to $3^{\text {rd }}$ month of postoperative values in all groups. After 3 months left ventricular posterior wall thickness was decreased by $36.21 \%, 29.78 \%$ and $17.58 \%$ in group A, group B and group C respectively. This study was consistent with the other studies ${ }^{13-14}$, where posterior wall thickness was reduced after surgical closure of VSD. However in that study no comparative study among different age groups was made.

Interventricular septal thickness increased from preoperative to $1^{\text {st }}$ month of postoperative values in all groups. After 1 month interventricular septal thickness was increased by $3.51 \%, 8.86 \%$ and $9.22 \%$ in group A, group $\mathrm{B}$ and group $\mathrm{C}$ respectively. It was significantly declined from preoperative values to $3^{\text {rd }}$ month of postoperative values in all groups and it was seen that interventricular septal thickness was decreased by $31.58 \%$, $25.00 \%$ and $16.67 \%$ in group A, group B and group C respectively after 3 months. This study was consistent with the other studies ${ }^{15-17}$, where interventricular septal thickness was reducing after surgical closure of VSD. However no comparative study among different age groups was made.

LA diameter increased from preoperative values to $1^{\text {st }}$ month of postoperative values in all groups. After 1 month it was increased by $4.81 \%, 4.28 \%$ and $4.75 \%$ in group A, group B and group C respectively. LA diameter was significantly declined from preoperative values to $3^{\text {rd }}$ month of postoperative values in all groups and it was seen that after 3 months LA diameter was decreased by $15.93 \%$, $12.84 \%$ and $5.96 \%$ in group A, group B and group C respectively. This study was consistent with the study done by Yuan et $\mathrm{al}^{14}$, where LA diameter was reducing one year after closure of VSD. However in that study no comparative study among different age groups was made. From this study it is evident that favorable left ventricular morphological changes occur when early surgical closure of VSD is done in relatively younger group of patients.

There are some limitations of the study. The sample size is smaller and it is a short term study. There are very papers existed on comparison between different age groups in terms of echocardiographic findings after surgical closure of VSD. Therefore, head to head comparison with other studies could not be done. A large, multicentric long term study can elucidate the optimum age for surgical closure of VSD in term of echocardiographic evidences of cardiac remodeling

\section{Conclusion:}

Comparison of degree of remodeling at $3^{\text {rd }}$ months between group A, group B and group C is significant in left ventricular posterior wall thickness, interventricular septal thickness, LA diameter. Cardiac remodeling observed after surgical closure of VSD in each age group. It has been 
observed that cardiac remodeling was better in group A compared to other age groups B and C. This study observed that cardiac remodeling occurred after surgical closure of ventricular septal defect and remodeling were more significant in younger age group.

\section{References:}

1. Minette MS, Sahn DJ. Ventricular septal defects. Circulation 2006; 114(20): 2190-2197

2. Rudolph AM. Ventricular septal defect. Congenital Diseases of the Heart: Clinical-Physiological Considerations, Third Edition 2009: 148-178

3. Penny DJ, Vick GW. Ventricular septal defect. The Lancet 2011; 377(9771): 1103-1112

4. Mavroudis C. Ventricular septal defect. Atlas of Pediatric Cardiac Surgery: Springer: 2015;99-115

5. Points KT. Ventricular septal defect. Learning Cardiac Auscultation: From Essentials to Expert Clinical Interpretation: 289

6. Hoffman JIE, Kaplan S. The incidence of congenital heart disease. J Am Coll Cardiol. 2002; 39: 1890-1900

7. Yang J, Yang L, Wan Y et al. Transcatheter device closure of perimembranous ventricular septal defects: mid-term outcomes. Eur Heart J 2010;31(18):2238-2245

8. Warnes CA, Liberthson R, Danielson GK, Dore A, Harris L, Hoffman J, Somerville J, Williams RG, Webb GD. Task Force 1: the changing profile of congenital heart disease in adult life. J Am Coll Cardiol. 2001; 37: 1170-1175

9. Hoffman JI, Kaplan S, Liberthson RR. Prevalence of congenital heart disease. Am Heart J. 2004; 147:425-439

10. Ishii M, Hashino K, Eto G, Tsutsumi T, Himeno W, Sugahara Y, Muta H, Furui J, Akagi T, Ito Y, Kato H. Quantitative assessment of severity of ventricular septal defect by threedimensional reconstruction of color Doppler-imaged vena contracta and flow convergence region. Circulation. 2001; 103: $664-669$

11. Scully BB, Morales DLS, Zafar F, McKenzie ED, Fraser CD, Heinle JS. Current expectations for surgical repair of isolated ventricular septal defects. The Annals of thoracic surgery 2010; 89(2): 544-551

12. Michel-Behnke I, Ewert P, Koch A et al. Device closure of ventricular septal defects by hybrid procedures: a multicenter retrospective study. Catheterization and Cardiovascular Interventions 2011; 77(2): 242-251

13. Berger RMF, Beghetti $M$, Gali $N$ et al. Atrial septal defects versus ventricular septal defects in BREATHE-5, a placebocontrolled study of pulmonary arterial hypertension related to Eisenmenger's syndrome: a subgroup analysis. International journal of cardiology 2010; 144(3): 373-378

14. Yuan L, Lei Z, Xudi, Hong Y, Ging KX, Rong Y, et al. A Follow up Study of Cardiac Function Evaluated by Echocardiography After Ventricular Septal Defect Occlusion. Acta Universitalis Medicinalis Nanjing 2010;07:172-1178

15. Chen FL, Hsiung MC, Nandos N, Hsien KS, Chou MC. Real time three-dimensional echocardiography in assessing ventricular septal defect: an echocardiographic surgical correlative study. Echocardiography 2006;23:562-568

16. Wang Q, Li Q, Zhang J, Wu Z, Zhou Q, Wang D-j. Ventricular septal defects closure using a minimal right vertical infraaxillary thoracotomy: seven-year experience in 274 patients. The Annals of thoracic surgery 2010; 89(2): 552-555

17. Allen HD, Driscoll DJ, Shaddy RE, Feltes TF. Moss \& Adams' Heart Disease in Infants, Children, and Adolescents: Including the Fetus and Young Adult edn): Lippincott Williams \& Wilkins, 2013

18. Tao K, Lin K, Shi Y et al. Perventricular device closure of perimembranous ventricular septal defects in 61 young children: early and midterm follow-up results. J Thoracic Cardio Surg 2010; 140(4): 864-870 